\title{
Faktor-Faktor yang Mempengaruhi Usahatani Selada Air di Desa Popnam Kecamatan Noemuti
}

\section{Yohanes Akoit}

Fakultas Pertanian, Universitas Timor, Kefamenanu, TTU - NTT, Indonesia.

\section{Article Info}

\section{Article history:}

Received 8 Desember 2017

Received in revised form 3 Juni 2018

Accepted 8 Juni 2018

DOI:

https://doi.org/10.32938/ag.v3i3.282

Keywords:

Faktor produki

Selada Air

\section{Abstrak}

Penelitian ini bertujuan untuk mengetahui 1) gambaran umum usahatani selada air; dan 2) faktor-faktor yang mempengaruhi usahatan selada air di Desa Popnam Kecamatan Noemuti. Kabupaten Timor Tengah Utara (TTU). Penelitian ini dilaksanakan di Desa Popnam Kecamatan Noemuti Kabupaten TTU pada bulan April 2017 sampai bulan Agustus 2017. Penentuan sampel dengan metode simple random sampling dengan cara menggunakan rumus slovin dimana jumlah sampel yang digunakan adalah 51 responden. Metode pengumpulan data dilakukan dengan metode survei. Data yang diambil berupa data primer dan data sekunder. Metode analisis data menggunakan metode deskriptif kualitatif dan analisis Cobb-Douglass. Hasil penelitian menunjukkan bahwa usahatani selada air di Desa Popnam dilakukan secara monokultur dengan luas lahan yang berbeda-beda berkisar antara 3-15 are. Tahapan usahatani yang dilakukan di lokasi penelitian antara lain persiapan lahan, pengolahan lahan, persiapan bibit, penanaman, pemeliharaan, panen dan pasca panen. Faktor modal, luas lahan, bibit, tenaga kerja, pengalaman usahatani dan pendidikan petani secara bersama-sama (simultan) berpengaruh nyata terhadap produksi selada air. Secara parsial faktor tenaga kerja dan pendidikan berpengaruh nyata terhadap produksi selada air, sedangkan variabel modal, luas lahan, bibit, dan pengalaman usahatani tidak berpengaruh nyata terhadap produksi usahatani selada air (C)2018 dipublikasikan oleh Agrimor.

\section{Pendahuluan}

Pembangunan pertanian selalu didorong untuk membangun keberlanjutan pembangunan ekonomi. Keberhasilan pembangunan pertanian ini ditentukan oleh lingkungan tumbuh dari komoditas pertanian tanaman pangan, hortikultura, perkebunan dan peternakan yang dihasilkan di lahan. Rangkaian kegiatan yang dilakukan ini sebagai upaya untuk meningkatkan pendapatan petani, menciptakan lapangan kerja, mengentaskan kemiskinan, memantapkan ketahanan pangan dan mendorong pertumbuhan ekonomi wilayah tersebut yang pada akhirnya memberikan manfaat bagi kesejahteraannya (Malta, 2011).

Sub sektor hortikultura merupakan komoditas yang cukup potensial dikembangkan secara agribisnis, karena punya nilai ekonomis dan nilai tambah yang cukup tinggi dibandingkan dengan komoditas lainnya. Menurut UndangUndang Nomor 13 Tahun 2010 tentang Hortikultura, komoditas hortikultura yang mencakup tanaman buah yakni suatu kelompok jenis tanaman hortikultura selain tanaman sayuran, tanaman bahan obat dan tanaman perkebunan yang keseluruhan atau bagian dari buahnya dapat dikonsumsi dalam keadaan segar maupun setelah diolah.

Selada air (Nasturtium officinale) adalah tumbuhan menahun yang cepa tumbuh, bersifat akuatik atau semi akuatik, asli Eropa dan Asia. Tumbuhan in adalah salah satu dari sayuran daun tertua yang dikonsumsi manusia (Priyadi, 2007). Selada air sangat mudah tumbuh dan sering ditemukan tumbuh liar di aliran sungai kecil, kolam, rawa, atau bagian danau yang dangkal (Muhlisah \& Sapta, 1997). Selada air kaya vitamin A dan mengandung banyak vitamin K, bersama dengan sejumlah antioksidan karotenoid dan phyochemical pelindung. Nutrien di dalam selada air mencegah kangker dan macular degeneration, membantu membangun sistim imun, dan mendukung kesehatan tulang. Zat besi membantu sel-sel darah merah membawa oksigen ke jaringan tubuh untuk energi (Pangkalan Ide, 2014).

Desa Popnam merupakan salah satu desa dari 12 Desa yang berada di wilayah Kecamatan Noemuti Kabupaten Timor Tengah Utara (TTU) yang menjadi sentra produksi tanaman hortikultura terlebih khusus tanaman selada air karena potensi wilayah sangat memungkinkan untuk mengusahakan komoditi ini. Berdasarkan survey awal produksi selada air pada tahun 2012 sebanyak 1 ton dengan luas lahan 1 ha, tahun 2013 sebanyak 1,5 ton dengan luas lahan 2 ha, tahun 2014 sebanyak 3 ton dengan luas lahan 3 ha, tahun 2015 sebanyak 3,5 ton dengan luas lahan 4 ha, tahun 2016 sebanyak 5 ton dengan luas lahan 5 ha. Produksi selada air mengalami peningkatan pada tahun 2012 hingga 2016.

Usahatani selada air yang dikembangkan di Desa Popnam Kecamatan Noemuti Kabupaten TTU, masih dalam tahap tradisional, dimana petani sudah memanfaatkan faktor-faktor produksi secara maksimal untuk meningkatkan produksi selada air. Hal tersebut dipengaruhi faktor-faktor produksi antara lain luas lahan, benih, tenaga kerja, modal, tingkat pendidikan, dan manajemen usahatani juga menjadi salah satu faktor yang menentukan tingkat keberhasilan usahatani selada air. Sejauh pengaruh dari variabel-variabel tersebut belum dapat digambarkan secara kuantitatif sehingga perlu dilakukan kajian tentang faktor-faktor yang mempengaruhi produksi usahatani selada air di Desa Popnam Kecamatan Noemuti. Penelitian ini bertujuan untuk mengetahui 1) gambaran umum usahatani selada air; dan 2) faktor-faktor yang mempengaruhi usahatani selada air di Desa Popnam Kecamatan Noemuti.

\section{Metode}

Penelitian dilaksanakan di Desa Popnam Kecamatan Noemuti Kabupaten TTU pada bulan Apri sampai Agustus 2017. Populasi dalam penelitian in adalah seluruh petani di Desa Popnam Kecamatan Noemuti yang berusahatani selada air. Penentuan sampel dilakukan dengan metode simple random sampling dengan rumus slovin sesuai petunjuk Bugin, (2005) dimana jumlah sampel yang digunakan adalah 51 responden. Pengumpulan data dalam penelitian ini dilakukan dengan cara wawancara dan observasi. Data yang digunakan berupa data primer dan data sekunder.
Untuk mengetahui tujuan pertama digunakan metode analisis deskriptif kualitatif sesuai petunjuk Sugiyono, (2006), sedangkan untuk mengetahui tujuan kedua digunakan model analisis Cobb-Douglas sesuai petunjuk Soekartawi, (1990). Secara matematis fungsi Cobb-Douglas dalam penelitian ini dituliskan $\mathrm{Y}=\mathrm{AX}_{1}{ }^{\mathrm{b} 1} \mathrm{X}_{2}^{\mathrm{b} 2}, \ldots \ldots, \mathrm{X}_{\mathrm{i}}^{\mathrm{bi}}, \ldots \mathrm{X}_{\mathrm{n}}^{\mathrm{bn}} \mathrm{e}^{\mathrm{u}}$. Fungsi Cobb-Douglas tersebut dinyatakan oleh hubungan $\mathrm{Y}$ dan $\mathrm{X}$ yakni $\mathrm{Y}=\mathrm{f}\left(\left(\mathrm{X}_{1}, \mathrm{X}_{2}, \mathrm{X}_{3}, \mathrm{X}_{4}, \mathrm{X}_{5}, \mathrm{X}_{6}\right)\right.$ dimana:

Y : Jumlah produksi selada air $(\mathrm{kg})$

$\mathrm{X}_{1}$ : Luas lahan (are)

$\mathrm{X}_{2}$ : Benih $(\mathrm{Kg})$

$\mathrm{X}_{3}$ : Modal (Rp)

$\mathrm{X}_{4}$ : Tenaga Kerja $(\mathrm{HKO})$

$\mathrm{X}_{5}$ : Tingkat Pendidikan (Tahun)

$\mathrm{X}_{6}$ : Pengalaman Usahatani (Tahun)

A,b : Besaran yang akan diduga

$\mathrm{U}_{1}$ : Kesalahan Pengganggu (disturbance term)

$b_{0}:$ intersep

e : Logaritma natural (2,7182)

Untuk memudahkan pendugaan terhadap persamaan di atas maka persamaan tersebut diubah menjadi bentuk linear berganda dengan cara melogaritmakan persamaan tersebut yang dituliskan $\mathrm{Ln} Y=\mathrm{Ln} a+\mathrm{b}_{1} \mathrm{Ln} \mathrm{X}_{1}+$ $b_{2} \operatorname{Ln~} X_{2}+\ldots .+b_{n} \operatorname{Ln} X_{n}+$ ei. Analisis data dilakukan menggunakan bantuan aplikasi SPSS.16 yang dilakukan sesuai petunjuk Santoso, (2008).

\section{Hasil dan Pembahasan}

3.1 Gambaran Usahatani Selada Air

a. Bahan Tanaman

Bahan tanaman yang digunakan adalah stek. Stek yang digunakan oleh petani responden dalam usahatani selada air di Desa Popnam tidak dibeli tetapi disediakan sendiri yaitu menanam kembali batang-batang tanaman selada air sisa panen. Panjang 10-15 cm bagian batang bawah yang dijadikan stek.

b. Persiapan Lahan

Sebelum stek disebarkan atau ditanam terlebih dahulu lahan disiapkan, Persiapan lahan meliputi pembalikan tanah menggunakan cangkul sekitar 30-40 $\mathrm{cm}$. Selanjutnya tanah didiamkan selama 7 hari menjelang penanaman agar sisa-sisa tanaman dan gulma mengalami penguraian. Setelah melewati masa peristirahatan tanah digembur secara manual. Tujuan dari penggemburan ini adalah memudahkan akar tanaman bebas mendapatkan unsur hara. Rata-rata curahan tenaga kerja yang digunakan untuk persiapan lahan sebanyak 4.94 HKO.

c. Penanaman

Setelah tanah digembur stek selada ditanam dengan cara dihamburkan secara merata sehingga pertumbuhannya pun merata. Selanjutnya air ditata sehingga stek yang telah dihambur tidak tergenang, apabila kelebihan air maka, stek akan mengalami pembusukan. Rata-rata curahan tenaga kerja yang digunakan untuk penanaman sebanyak 1.08 HKO.

d. Penyiangan

Penyiangan dilakukan saat tanaman berumur 2 minggu setelah tanam atau saat gulma tumbuh di sekitar tanaman caranya mencabut rumput-rumput di tepi pematang menggunakan sabit. Rata-rata curahan tenaga kerja yang digunakan untuk penyiangan sebanyak 3.08 HKO.

e. Panen dan Pasca Panen

Pemanenan selada dilakukan pada umur 40 hari setelah tanam dengan cara memetik secara manual yaitu dengan menggunakan tangan. Jika pemanenan terlambat maka batang selada akan membengkok ke bawah bahkan menjalar dan batang semakin tua dan berserat sehingga tidak diminati konsumen. Pasca Panen merupakan tahap akhir dari kegiatan usahatani dimana selada yang telah dipetik diikat menggunakan tali gewang dan siap untuk dipasarkan. Rata-rata curahan tenaga kerja yang digunakan untuk panen sebanyak-banyak 2.60 HKO. $b^{1} \quad$ : Koefisien regresi faktor produksi ke $-i(i=1,2,3,4,5)$ 


\subsection{Faktor-Faktor yang Mempengaruhi Produksi Selada Air}

Analisis yang digunakan pada penelitian ini adalah analisis regresi berganda dalam bentuk logaritma dengan fungsi produksi Cobb-Douglas. Model matematis fungsi produk Cobb-Douglas dengan metode Ordinary Least Square (OLS). Fungsi Cobb-Douglas digunakan untuk menguji pengaruh antara variabel independen terhadap produksi selada air. Hasil Cobb-Douglas dapat dilihat pada Tabel 1 .

Tabel 1. Analisis Varians

\begin{tabular}{ccccccc}
\hline \multirow{2}{*}{ Model } & \multicolumn{2}{c}{$\begin{array}{c}\text { Unstandardized } \\
\text { Coefficients }\end{array}$} & $\begin{array}{c}\text { Standardized } \\
\text { Coefficients }\end{array}$ & $\begin{array}{c}\mathrm{T} \\
\text { nitung }\end{array}$ & T tabel & Sig. \\
\cline { 2 - 4 } & $\mathrm{B}$ & Std. Error & Beta & & & \\
\hline (Constant) & 2.099 & 1.693 & & 1.240 & 1,677 & 0,225 \\
$\mathrm{X}_{1}$ & 0,140 & 0,099 & 0,184 & 1.408 & & 0,170 \\
$\mathrm{X}_{2}$ & 1008,725 & 0,514 & 0,408 & 1.325 & 0,196 \\
$\mathrm{X}_{3}$ & 0,649 & 0,372 & 0,537 & 1.744 & 0,092 \\
$\mathrm{X}_{4}$ & 0,960 & 0,144 & 0,754 & 6.682 & 0,000 \\
$\mathrm{X}_{5}$ & $-7,900$ & 0,127 & 0,090 & $-0,776$ & 0,444 \\
$\mathrm{X}_{6}$ & 0,519 & 0,143 & 0,386 & 3.626 & 0,001 \\
\hline
\end{tabular}

Berdasarkan Tabel 1. diperoleh persamaan regresi linear berganda yang dimana persamaan regresi yakni $Y=2.099+0,140 X_{1}+1008,725 X_{2}+0,649 X_{3}$ $+0,960 \mathrm{X}_{4}-7,900 \mathrm{X}_{5}+0,519 \mathrm{X}_{6}$.

Koefisien determinasi $\left(\mathrm{R}^{2}\right)$ digunakan untuk melihat seberapa besar variabel independen (modal, luas lahan, bibit, tenaga kerja, pengalaman usahatani, pendidikan) menjelaskan variabel dependen (produksi).

Tabel 2. Koefisien Determinasi $\left(\mathrm{R}^{2}\right)$

\begin{tabular}{ccccc}
\hline Model & $\mathrm{R}$ & $\mathrm{R}$ Square & $\begin{array}{c}\text { Adjusted R } \\
\text { Square }\end{array}$ & $\begin{array}{c}\text { Std. Error of } \\
\text { the Estimate }\end{array}$ \\
\hline 1 & $0,849^{\mathrm{a}}$ & 0,720 & 0,660 & 0,26915 \\
\hline
\end{tabular}

Data Tabel 2. Menunjukan bahwa nilai $\mathrm{R}^{2}$ sebesar 0,720 atau mencapai $72 \%$, angka tersebut menunjukkan bahwa kemampuan variabel modal, luas lahan, bibit, tenaga kerja, pengalaman usahatani, pendidikan dalam memberikan informasi untuk menjelaskan keragaman variabel produksi sebesar $72 \%$ terhadap peningkatan maupun penurunan produksi sedangkan sisanya $28 \%$ dipengaruhi oleh faktor lain yang tidak diteliti dalam penelitian ini.

Uji F dilakukan untuk melihat bagaimana variabel independen (modal, luas lahan, bibit, tenaga kerja, pengalaman usahatani, pendidikan petani) secara bersama-sama atau simultan mempengaruhi variabel dependen faktor produksi selada air.

Tabel 3. Analisis $\mathrm{F}_{\text {hitung }}$

\begin{tabular}{lcccccc}
\hline \multicolumn{1}{c}{ Model } & $\begin{array}{c}\text { Sum of } \\
\text { Squares }\end{array}$ & df & $\begin{array}{c}\text { Mean } \\
\text { Square }\end{array}$ & $\begin{array}{c}\text { F } \\
\text { hitung }\end{array}$ & $\begin{array}{c}\text { F } \\
\text { tabel }\end{array}$ & Sig. \\
\hline Regression & 5.217 & 6 & 0,869 & 12.002 & 1,91 & $0,000^{\mathrm{a}}$ \\
Residual & 2.028 & 28 & 0,072 & & & \\
\hline Total & 7.245 & 34 & & & & \\
\hline
\end{tabular}

Data Tabel 3. Menunjukkan bahwa nilai signifikasi sebesar 0,000 atau lebih kecil dari 0,005 sehingga dapat dikatakan bahwa variabel bebas yang meliputi modal, luas lahan, bibit, tenaga kerja, pengalaman usahatani, pendidikan petani secara bersama-sama memiliki pengaruh nyata terhadap produksi selada air.

Uji t dilakukan untuk mengetahui pengaruh variabel bebas yang diteliti secara individual terhadap produksi selada air di Desa Popnam. Berdasarkan data Tabel 1. maka pengaruh secara parsial dari faktor modal, luas lahan, bibit, tenaga kerja, pengalaman usahatani dan pendidikan petani terhadap produksi selada air dapat diuraikan sebagai berikut:

a. $\operatorname{Modal}\left(\mathrm{X}_{1}\right)$

Modal dalam penelitian ini adalah besarnya modal yang digunakan oleh petani dalam berusahatani selada air. Hasil analisis data diperoleh signifikasi sebesar 0,170 atau lebih besar dari 0,05 yang berarti variabel modal tidak berpengaruh nyata terhadap produksi usahatani selada air.

b. Luas Lahan $\left(\mathrm{X}_{2}\right)$

Luas lahan dalam penelitian ini adalah besarnya luas lahan yang digunakan oleh petani dalam berusahatani selada air. Hasil analisis data diperoleh signifikasi sebesar 0,196 atau lebih besar dari 0,05 yang berarti variabel luas lahan tidak berpengaruh nyata terhadap produksi usahatani selada air.

c. Bibit $\left(\mathrm{X}_{3}\right)$

Bibit dalam penelitian ini adalah jumlah bibit yang digunakan oleh petani dalam satu kali tanam. Hasil analisis data diperoleh signifikasi sebesar 0,092 atau lebih besar dari 0,05 yang berarti variabel bibit tidak berpengaruh nyata terhadap produksi usahatani selada air.

d. Tenaga Kerja $\left(\mathrm{X}_{4}\right)$

Tenaga Kerja dalam penelitian ini dihitung dalam HKO dan tenaga kerja berasal dari dalam keluarga responden itu sendiri, sehingga tenaga kerja tidak diupah dan hasil penelitian menunjukkan bahwa tenaga kerja cukup banyak pada kegiatan pemanenan, dan kegiatan pemanenan dilakukan 2 kali panen sehingga membutuhkan curahan tenaga kerja yang cukup banyak. Hasil analisis data diperoleh signifikasi sebesar 0,000 atau lebih kecil dari 0,05 yang berarti variabel tenaga kerja berpengaruh nyata terhadap produksi usahatani selada air. Dapat dikatakan bahwa pengaruh tenaga kerja adalah positif artinya setiap penambahan $1 \%$ tenaga kerja akan meningkatkan hasil produksi selada air sebesar 6,682 dengan asumsi bahwa variabel lain dianggap tetap. Alasannya karena petani yang menggunakan tenaga kerja yang banyak produksinya akan berbeda jauh dengan petani yang menggunakan tenaga kerja yang sedikit. e. Pengalaman Usahatani $\left(\mathrm{X}_{5}\right)$

Pengalaman yang dimaksudkan dalam penelitian ini adalah pengalaman responden dalam berusahatani selada air. Hasil analisis data diperoleh signifikasi sebesar 0,444 atau lebih besar dari 0,05 yang berarti variabel pengalaman usahatani tidak berpengaruh nyata terhadap produksi usahatani selada air.

f. Pendidikan $\left(\mathrm{X}_{6}\right)$

Pendidikan yang dimaksudkan dalam penelitian ini adalah pendidikan yang ditempuh oleh petani mulai dari jenjang SD sampai SMA. Hasil analisis data diperoleh signifikasi sebesar 0,001 atau lebih kecil dari 0,05 yang berarti variabel pendidikan berpengaruh nyata terhadap produksi usahatani selada air. Alasannya karena petani yang berpendidikan rendah lebih lambat dalam mengadopsi teknologi baru yang dapat meningkatkan produksi sebaliknya dengan pendidikan tinggi, petani akan mudah menerima inovasi teknologi.

\section{Simpulan}

Usahatani selada air di Desa Popnam dilakukan secara monokultur dengan luas lahan yang berbeda-beda berkisar antara 3-15 are. Tahapan usahatani yang dilakukan di lokasi penelitian antara lain persiapan lahan, pengolahan lahan, persiapan bibit, penanaman, pemeliharaan, panen dan pasca panen. Faktor modal, luas lahan, bibit, tenaga kerja, pengalaman usahatani dan pendidikan petani secara bersama-sama (simultan) berpengaruh nyata terhadap produksi selada air. Secara parsial faktor tenaga kerja dan pendidikan berpengaruh nyata terhadap produksi selada air, sedangkan variabel modal, luas lahan, bibit, dan pengalaman usahatani tidak berpengaruh nyata terhadap produksi usahatani selada air.

\section{Pustaka}

Bugin, H.M.B. 2005. Metodologi Penelitian Kuantitatif. Jakarta: Kencana.

Malta, M. 2011. Faktor-Faktor yang Berhubungan dengan Kinerja Petani Jagung di Lahan Gambut. MIMBAR, Jurnal Sosial dan Pembangunan, 27(1): 67-78

Muhlisah, F. \& Sapta, H. 1997. Sayur dan Bumbu Dapur Berkhasiat Obat. Jakarta: Penebar Swadya.

Pangkalan Ide 2014. Agar Otak Sehat. Jakarta: Elex Media Komputindo.

Priyadi, S. 2007. Pertumbuhan Dan Produktivitas Selada Air (Nasturtium Officinale) Pada Berbagai Tinggi Genangan Di Desa Kaligiri, Kabupaten Brebes-Jawa Tengah. Skripsi. Bogor: Institut Pertanian Bogor.

Santoso, S. 2008. Panduan Lengkap Menguasai Spss 16. Jakarta: Elex Media Komputindo.

Soekartawi 1990. Teori Ekonomi Produksi dengan Pokok Bahasan Analisis Fungsi Cobb-Douglas. Depok: Rajawali Pers.

Sugiyono, 2006. Metode Penelitian Kuantitatif, Kualitatif dan $R \& D$. Bandung: Alfabeta.

Undang-Undang Nomor 13 Tahun 2010 tentang Hortikultura. 